\title{
Congenital hyperinsulinism of the newborn: a case report
}

\author{
Hiperinsulinismo congénito del recién nacido. A propósito de un caso clínico
}

\author{
Josefina Sáez ${ }^{\mathrm{a}}$, Juan Carlos Pattillo ${ }^{\mathrm{b}}$, Pilar Orellana ${ }^{\mathrm{c}}$, Claudia Godoy ${ }^{\mathrm{d}}$
}

aGeneral Surgery Resident, Faculty of Medicine, Pontificia Universidad Católica de Chile

bPediatric Surgery, Division of Surgery, Faculty of Medicine, Pontificia Universidad Católica de Chile

cNuclear Medicine, Radiology Department, Faculty of Medicine, Pontificia Universidad Católica de Chile

dPediatric Endocrinology, Division of Pediatrics, Faculty of Medicine, Pontificia Universidad Católica de Chile

Received: 27-4-2016; Accepted: 17-12-2016

\begin{abstract}
Congenital hyperinsulinism (HC) is the most frequent cause of persistent hypoglycemia in the newborn and it is characterized by an inappropriately elevated insulin level in presence of hypoglycemia. Initial management is medical treatment, but if it fails, partial pancreatectomy is the surgical procedure of choice. Objective: To report a case of a newborn with $\mathrm{CH}$ to aware on this condition and update its multidisciplinary management. Case report: The case of a full term newborn with severe symptomatic hypoglycemia unresponsive to medical treatment is reported. Ultrasonography and abdominal MRI were normal, Gallium 68 PET/CT showed uptake in the body of the pancreas. Laparoscopic corporocaudal pancreatectomy was performed. The patient resolved hypoglycemia and was discharged without incidents. Genetic study was consistent with focal $\mathrm{CH}$, confirmed later by biopsy. Discussion: This case report exposes the clinical presentation of $\mathrm{CH}$ and its diagnosis. It emphasizes on the surgical treatment and the advantages of minimally invasive technique.
\end{abstract}

\author{
Keywords: \\ Congenital \\ hyperinsulinism; \\ newborn; \\ pancreatectomy; \\ laparoscopy.
}

\section{Introduction}

Congenital hyperinsulinism (HC) is the main cause of persistent and recurrent hypoglycemia in the first year of life $\mathrm{e}^{1-3}$. Its incidence ranges from $1 / 27,000$ to $1 / 50,000$ in newborns ${ }^{4}$. Laidlaw described it in 1938 and called it 'Nesidioblastosis'. It is currently described as a heterogeneous condition in clinical presentation, genetics, histology and response to treatment ${ }^{3}$.

$\mathrm{HC}$ is characterized by inadequate and unregulated in- sulin production when blood glucose levels are low $^{6}$. Insulin secretion by pancreatic $\beta$ cells is controlled to maintain fasting glucose normally between 63 and $99 \mathrm{mg} / \mathrm{dl}^{7}$.

The importance of early diagnosis and treatment lies in neurological damage secondary to hypoglycemic states, which may be permanent ${ }^{1-3,8}$. Management requires metabolic stabilization with glucose supply and decrease insulin secretion, which is mainly achieved with diazoxide or somatostatin analogues (Octreotide) ${ }^{9-11}$.

If glycemic control is not steady with medical mana- 
gement, surgical treatment should be considered ${ }^{3,6}$. In order to plan the surgery, it is important to know if the lesion that produces HC is histologically diffuse, focal or atypical ${ }^{6}$. For this reason, genetic and/or imaging study is useful, as Fluorine 18-L-3,4 Dihydroxyphenylalanine Positron Emission Tomography (18F-DOPA-PET/CT scan $)^{12,13}$. If the lesion is diffuse, the surgery of choice is subtotal pancreatectomy. However, if this is focalized, a resection of the lesion will be preferred ${ }^{13,14}$. Along with the progress of the minimally invasive technique, laparoscopic surgery became an effective and safe alternative in the pediatric population ${ }^{15}$. In our country there are reports of the use of this technique in pancreatic pathology in children ${ }^{16,17}$. However, according to our search, it would not be described as an option for HC cases in newborns.

The objective of this article is to report a case of focalized HC, which was successfully treated with minimally invasive surgery, and also to discuss its multidisciplinary confrontation.

\section{Clinical case}

39 week-old male newborn, birth weight $4,255 \mathrm{~g}$ and length $53.5 \mathrm{~cm}$. He is the second son of healthy non-consanguineous parents with a 3-year-old healthy sister. The mother underwent pregnancy with fasting hyperglycemia managed with diet (glycosylated HbAlc $4.9 \%)$. Cesarean delivery due to fetal dystocia was performed. He did not present any congenital anomalies or physical dysmorphia. His capillary glycemia at 2 hours of life was normal.

At 17 hours of life, he presented drowsiness, hypotonia, respiratory distress and weak suction. Glycemia $28 \mathrm{mg} / \mathrm{dl}$, Insulin $30 \mathrm{IU} / \mathrm{L}$ (N.V. suppressed) and Cortisol $10.9 \mu \mathrm{g} / \mathrm{dl}$ (N.V. > 18). The second sample showed glycemia levels of $33 \mathrm{mg} / \mathrm{dl}$, Insulin $23 \mathrm{IU} / \mathrm{L}$ and negative ketonemia, which confirmed HC. He required intravenous glucose up to $17 \mathrm{mg} / \mathrm{kg} / \mathrm{min}$, and intravenous Hydrocortisone at an initial dose of $50 \mathrm{mg} / \mathrm{m}^{2} /$ day. On the fifth day oral Diazoxide was started progressively from 5 to $20 \mathrm{mg} / \mathrm{kg} / \mathrm{day}$ and Hydrochlorothiazide $2 \mathrm{mg} / \mathrm{kg} /$ day, without effective response. At 20 days of life, Octreotide was started with a dose up to $30 \mu \mathrm{g} / \mathrm{kg} / \mathrm{per}$ day (initially in continuous intravenous infusion and then subcutaneous infusion every 6 hours). Intravenous Glucagon was added $(5 \mu \mathrm{g} /$ $\mathrm{kg}$ /hour). With this, glucose requirements decreased to $4 \mathrm{mg} / \mathrm{kg} / \mathrm{min}$ without achieving normoglycemia.

Ultrasound and MRI of the abdomen were normal. PET/CT with Gallium 68 reported focal area of overexpression of somatostatin receptors at the body-tail union of the pancreas (figure 1).
The genetic study of hyperinsulinism at the Wellcome Wolfson Medical Research Center, University of Exeter Medical School, UK, revealed a heterozygous missense mutation in the exon 35 gene of the ABCC8 gene, p.Ser1423Pro inherited from the father, asymptomatic carrier, while maternal genetic study was normal.

Clinical manifestations, the genetic study and the $\mathrm{PET} / \mathrm{CT}$ image allowed us to conclude that the HC corresponded to a focal pancreatic lesion.

A laparoscopic corporocaudal pancreatectomy was planned and performed at 37 days of life. The abdomen was accessed in supine position through an infraumbilical incision, with open technique. $\mathrm{A} \mathrm{CO}_{2}$ heater was used with $10 \mathrm{mmHg}$ of pressure with a maximum flow of $3 \mathrm{lpm}$. Two $5 \mathrm{~mm}$ trocars were used, one for access and other in the left iliac fossa for coagulation instruments, plus two $3 \mathrm{~mm}$ instruments inserted percutaneously into the abdomen. The dissection was initiated by accessing the lesser sac, being aware of the gastroepiploic vessels. The stomach was sutured to the anterior abdominal wall, achieving optimal visualization of the pancreas. The release of the splenic angle of the colon allowed access to the splenic hilum and tail of the pancreas. With the use of monopolar and bipolar coagulation and Ligasure (R), the pancreas was separated from the branches of the splenic vein from the tail to the body. A nodular lesion of increased consistency was identified, very attached to the splenic vein (figure 2). Proximal dissection allowed the identification of the superior mesenteric vein, the portal vein and the hepatic artery. A retropancreatic tunnel was opened; the pancreas was sectioned and ligated with Endoloop (R). During separation of the splenic vein tumor, patient started to bleed, requiring ligation of the splenic vessels with Hemolock (R) to achieve hemostasis. The pancreas was removed by the umbilical wound and no drainage was used. At the end, the spleen was moderately ischemic without engorgement.

The biopsy described pancreatic tissue of partially distorted architecture, with irregular aggregates of islets of Langerhans mixed with ductoinsular complexes, delimited with immunohistochemistry of neuroendocrine markers (chromogranin, synaptophysin, CD56). The rest of the sample reported preserved morphology, neuroendocrine cells dispersed positive in immunohistochemistry mentioned, and that did not conform a lesion.

The patient progressed favorably, rapidly achieving normal glycemia without medication and was discharged 10 days after surgery.

At 18 months of age, he remains eutrophic, normoglycemic and has normal psychomotor development. Ultrasonography shows spleen of normal size and perfusion. 


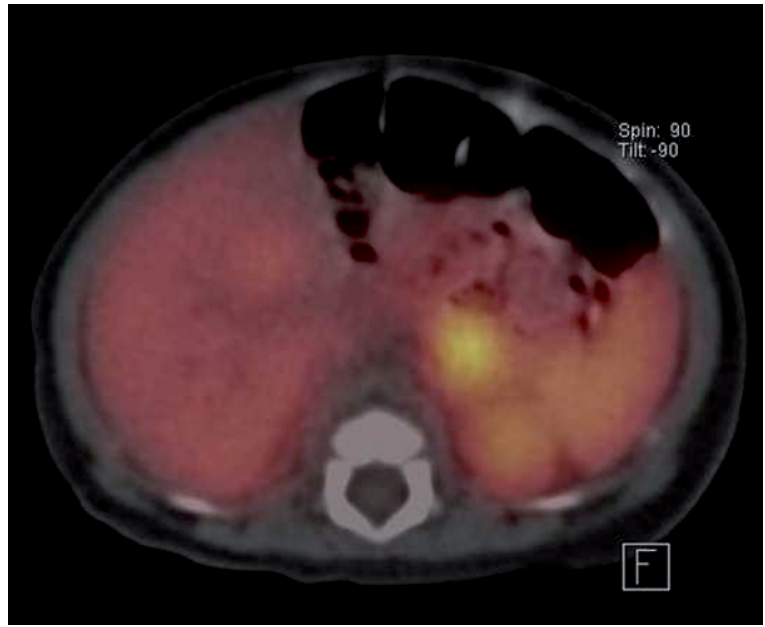

Figure 1a. PET CT, cross section. Notice the area with hypercaptation of radioligand in relation to ody-tail of the pancreas.

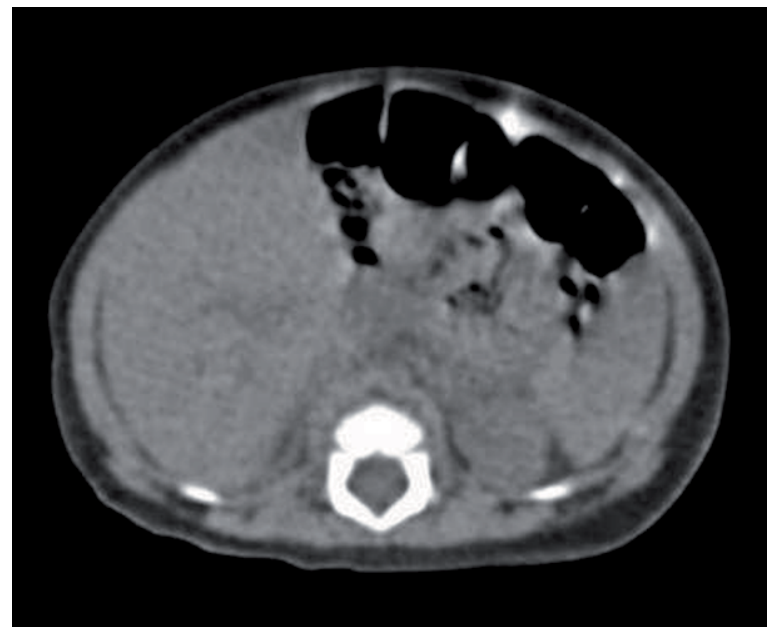

Figure 1b. CT without contrast, cross section at Figure 1a level There is no image correlated to the area of hypercaptation described in PET CT.

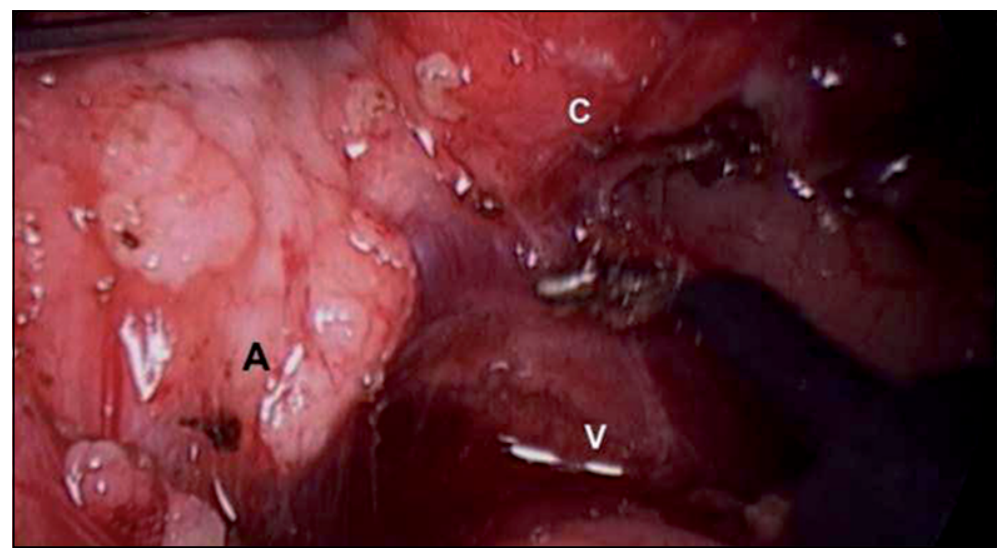

Figure 2. Capture of video image in laparoscopic surgery. The nodular area described in relation to the body of the pancreas (A) and the tail (C) is observed. It is also identified the splenic vein (V), structure with which the nodular zone was closely related.

\section{Discussion}

$\mathrm{HC}$ is an uncommon disorder of glucose metabolism, which is the most common cause of persistent hypoglycemia of the newborn ${ }^{1-3}$. Its pathogenesis lies in excessive production of insulin by pancreatic $\beta$ cells, even with low blood glucose levels 8 .

The diagnosis is suspected in cases of persistent hypoglycemia or poor tolerance to fasting $(<1 \mathrm{hr})$, unresponsive to oral intake, and requiring very high glucose loads $(>8 \mathrm{mg} / \mathrm{K} / \mathrm{min})^{3,6,9}$. They are usually macrosomic newborns, but they have been reported with normal weight or even small ${ }^{18}$.

Symptoms may be mild and nonspecific (lethargy, poor sucking, irritability) or even severe, such as apnea, seizures and loss of consciousness (coma) $)^{6}$.

Insulin and C-peptide levels are inappropriately elevated compared to hypoglycemia. In addition, low levels of free fatty acids and ketones can be observed by inhibition of lipolysis ${ }^{1,6,18}$. This increases the risk of brain injury. The favorable response to Glucagon and somatostatin analogs also is an indicator ${ }^{18}$.

It is possible to find low levels of cortisol in relation to hypoglycemia in neonates with $\mathrm{HC}$, corresponding to an inappropriate transient response of the hypothalamic-pituitary axis to produce ACTH ${ }^{19}$.

Persistent hypoglycemia produced by HC may have negative consequences on neurological development. Therefore is necessary an aggressive approach ${ }^{1}$. The goal is to achieve adequate blood glucose levels (> $60 \mathrm{mg} / \mathrm{dl}$ ) with intravenously and oral intake. Glucagon can be administered to raise blood glucose ( $5 \mathrm{ug} / \mathrm{k} / \mathrm{hour}$ ). The Insulin excess is treated with drugs, being the first choice Diazoxide $(5-20 \mathrm{mg} / \mathrm{kg} /$ day orally) that keeps the $\mathrm{K}_{\mathrm{ATP}}$ sensitive channels open ${ }^{3,6,10}$. If there is no response, it is suggested to treat with somatostatin analogs such as Octreotide $(5-35 \mathrm{mcg} / \mathrm{kg} /$ day in bolus or continuous subcutaneous infusion) $)^{3,11}$. 
Other drugs used less frequently are Nifedipine and Sirolimus ${ }^{20}$.

Patients who despite fractional feeding and pharmacological therapy, need intravenous glucose to maintain normoglycemia, are considered resistant to medical treatment, and a surgical solution should be considered $^{3,10,11}$. Hussain proposes first-line surgical management in focal HC and in diffuse HC that does not react to pharmacological treatment ${ }^{3,6,10-11,13}$, which belongs approximately to $65 \%$ of $\mathrm{HC}$ cases $^{21}$.

Although the clinical presentation can be distinctive, $\mathrm{HC}$ is a heterogeneous, histological and genetic condition. Histopathology describes adenomatous hyperplasia of the pancreas, which may be diffuse or focal, although a third atypical form has been identified, which mixes healthy and abnormal islets ${ }^{11}$. The molecular mechanism is different in each case $e^{3,4,7}$. The diffuse form is related to autosomal recessive inheritance and the focal is usually sporadic and has a lower risk of recurrence ${ }^{11}$.

Currently, it is possible to know the histological type with the use of the genetic study and PET/CT ${ }^{3,6}$.

Genetic alteration has been identified in $50 \%$ of HC patients, corresponding to mutations of nine genes related to insulin secretion ${ }^{3,4,7,11} .36 \%$ are "channelopathies", which alter the functioning of the $\beta$-cell $\mathrm{K}_{\text {ATP }}$ sensitive channel. Of these, the ABCC8 gene encodes for the sulfonylurea receptor (SUR1) and the KCNJ11 encodes for the Kir 6.2 subunit. They cause permanent closure of the channel, producing a continuous depolarization of the $\beta$-cell and uncontrolled secretion of insulin ${ }^{7}$. Channelopathies (ABCC8 and $\mathrm{KCNJ11)}$ are usually recessive conditions, generating more severe HC. They are more resistant to medical treatment than dominant ones, which have an unaffected allele ${ }^{3,7}$.

Focal lesions require the succession of two events: a recessive $K_{\mathrm{ATP}}$ sensitive mutation of paternal origin, followed by the postzygotic loss of heterogeneity of the $11 \mathrm{p} 15.1$ region. This results in paternal isodisomy of the $\mathrm{K}_{\text {ATP }}$ sensitive mutation and adjacent locus region, which contains imprinted genes (H19, IGF2, CDKN1C) that lead to islet overgrowth ${ }^{22}$.

The other seven genes (GLUD 1, HADH, GCK, SLC16A1, HNF4A, HNF1A, UCP2) produce alterations called "metabolopathies" that alter metabolic pathways whose end product is insulin hypersecretion. They are rare diseases, of dominant inheritance ${ }^{7}$. Genetic analysis is not available in our country and is only carried out in specialized centers ${ }^{23}$. The case study was conducted at The Wellcome Wolfson Medical Research Center-University of Exeter Medical School in England and demonstrated a channelopathy with mutation in the ABCC8 gene. Since it is of paternal inheritance, it is concordant with a focal lesion that will not respond to medical treatment, so the location of the lesion in the pancreas becomes indispensable.

The images are particularly useful to rule out the presence of insulinomas ${ }^{24,25}$. This could be identified with ultrasonography, endosonography, computed tomography or abdominal MRI ${ }^{24,25}$. However, these procedures fail to define whether the HC lesion is focal or diffuse, which is crucial to decide the treatment, plan the extension of pancreatic resection and evaluate the prognosi ${ }^{25-28}$. Recent studies emphasize the contribution of Fluorine 18-L-3,4 Dihydroxyphenylalanine Positron Emission Tomography (18F-DOPA-PET/CT scan) which reports a $96 \%$ accuracy in differentiating diffuse or focal disease, making precise the localization of a focal lesion in up to $100 \%$ of cases s $^{3,25,27,28}$. It should be done when it is verified that the $\mathrm{HC}$ is persistent (usually after 1 month of life) and could be overlooked if the genetic study demonstrates diffuse disease ${ }^{28}$.

$18 \mathrm{~F}-\mathrm{DOPA}$ is not available in our country. Since the patient responded partially to somatostatin analogues, the study was performed with Gallium 68 , which adheres to somatostatin receptors, and showed a focal lesion that helped to plan the extent of pancreatectomy.

Focal lesions can be completely cured with partial pancreatectomy or enucleation, while for diffuse form subtotal resection is suggested, and $85-95 \%$ of the pancreatic mass should be removed, although relapses may occur and require reintervention.

The most frequent complications of subtotal surgery are infections in the acute phase, development of Diabetes Mellitus, and deficiency in exocrine pancreatic function in the long term ${ }^{6,28}$. In a cohort of children with subtotal pancreatectomy for HC, it was reported that up to $60 \%$ required maintaining medical treatment because hypoglycemia persisted. The incidence of Diabetes Mellitus was $96 \%$ and biochemical exocrine pancreatic insufficiency was $72 \%$ at 11 years of follow-up ${ }^{29}$.

With the development of minimally invasive techniques, laparoscopic pancreatic surgery has demonstrated its effectiveness and safety, even better cosmetic result, less postoperative pain and physiological impact on patients and reduced development of postoperative adhesions ${ }^{16-17,30-32}$. The first report of laparoscopic pancreatectomy in a pediatric patient with diffuse disease was published in $2001^{32}$ and laparoscopic enucleation of focal lesions in $2003^{33}$. Since then, several pediatric series of laparoscopic HC surgery have been published in english literature ${ }^{27,30-33}$. Its efficacy has been shown to be comparable to the classical technique, although it requires advanced skills in laparoscopy because it is an area where dissection is near large vessels, and is more complex if the lesion involves the head of the pancreas. Laparoscopy offers the advantage of an amplified view 
of the image and better visualization of anatomical structures. Given the likehood that some patients require a reoperation, this should be the choice in the first surgery ${ }^{30}$.

In our patient, the surgery was laparoscopic and with complete resection of the focus. No relapse or development of endocrine or exocrine pancreatic insufficiency should be expected.

In conclusion, $\mathrm{HC}$ is a rare disease, but it is the first cause of persistent hypoglycemia in the newborn, and its confrontation must be fast and aggressive. The study should be oriented to discriminate the diffuse and focal forms, having a fundamental role the PET/CT and the use of genetic studies. In focal forms and in hyperinsulinism refractory to medical management, surgery is the treatment of choice and the extent of resection will depend on the clinical stage. Laparoscopic pancreatic surgery in the newborn is feasible and has advantages over the open technique, but should be performed by teams with experience in advanced laparoscopy.

\section{Ethical Responsibilities}

Human Beings and animals protection: Disclosure the authors state that the procedures were followed according to the Declaration of Helsinki and the World Medical Association regarding human experimentation developed for the medical community.
Data confidentiality: The authors state that they have followed the protocols of their Center and Local regulations on the publication of patient data.

Rights to privacy and informed consent: The authors have obtained the informed consent of the patients and/or subjects referred to in the article. This document is in the possession of the correspondence author.

\section{Financial Disclosure}

Authors state that no economic support has been associated with the present study.

\section{Conflicts of Interest}

Authors state that any conflict of interest exists regards the present study.

\section{Acknowledgements}

The authors would like to thank Neonatology, Pediatric Surgery and Hepatobiliopancreatic Surgery teams, from the Faculty of Medicine, for their invaluable contributions. Particularly, we acknowledge Dr Khalid Hussain from the Pediatric Endocrinology Department of Great Ormond Street Hospital for Children NHS Trust, Londres, for his assistance in the genetic study.

\section{References}

1. Ludwig A, Ziegenhorn K, Empting S, et al. Glucose metabolism and neurological outcome in congenital hyperinsulinism. Semin Pediatr Surg 2011;20:45-9.

2. Avatapalle HB, Banerjee I, Shah S, et al. Abnormal neurodevelopmental outcomes are common in children with transient congenital hyperinsulinism. Front Endocrinol (Lausanne) 2013;4:60.

3. Yorifuji T. Congenital hyperinsulinism: current status and future perspectives. Ann Pediatr Endocrinol Metab 2014; 19:57-68.

4. Glaser B, Thornton P, Otonkoski $\mathrm{T}$, Junien C. Genetics of neonatal hyperinsulinism. Arch Dis Child Fetal Neonatal 2000;82:F79-F86.

5. Laidlaw GF. Nesidioblastoma, the islet cell tumor of the pancreas. Am J Pathol 1938; 14:125-34.

6. Shah P, Demirbilek H, Hussain K. Persistent hyperinsulinaemic hypoglycaemia in infancy. Sem Pediatr Surg 2014; 23: 76-82.

7. Rahman S, Nessa A, Hussain K.
Molecular mechanism of congenital hyperinsulinism. J Mol Endocrinol 2015;54 (2):R119-29.

8. Lovvorn III H, Nance M, Ferry R, et al. Congenital hyperinsulinism and the surgeon: Lessons learned over 35 years. J Pediatr Surg 1999; 34:786-93.

9. Hoe FM, Thornton PS, Wanner LA, et al. Clinical features and insulin regulation in infants with a syndrome of prolonged neonatal hyperinsulinism. J Pediatr 2006;148:207.

10. Hussain K, Aynsley-Green A. Management of hyperinsulinism in infancy and childhood. Ann Med 2000;32(8):544-51.

11. Kapoor RR, James C, Hussain K. Advances in the diagnosis and management of hyperinsulinemic hypoglycemia. Nat Clin Pract Endocrinol Metab 2009;5(2):101-12.

12. Mohamed Z, Arya VB, Hussain K. Hyperinsulinaemic hypoglycaemia: genetic mechanisms, diagnosis and management. J Clin Res Pediatr Endocrinol. 2012;4(4):169-81.

13. Hussain K. Diagnosis and management of hyperinsulinaemic hypoglycaemia of infancy. Horm Res 2008;69(1):2-13.

14. Tanaka $\mathrm{Y}$, Asakawa T, Asagiri $\mathrm{K}$ Ayikoshi K, Hikida S, Mizote H. Nesidioblastosis treated successfully by $85 \%$ pancreatectomy. Kurume Medical J 2004;51:99-103.

15. Al-Shanafey S, Habib Z, Alanzar S. Laparoscopic pancreatectomy for persistent hyperinsulinemic hypoglycemia of infancy. J Pediatr Surg 2009;44:134-8.

16. Slako M, Muñoz C, Briceño E, et al. Tumor sólido pseudopapilar del páncreas: estudio descriptivo de una serie de casos. Rev Chil Cir. 2012;64(3):251-6.

17. Pattillo J, Jarufe N. Avances en la cirugía de tumores del páncreas exocrino en niños. Rev Chil Pediatr. 2013 84(4):41724.

18. Hernández M I, Hodgson M I, Cattani A. Hiperinsulinismo neonatal persistente. Análisis del diagnóstico diferencial a propósito de dos casos clínicos. Rev Med Chile 2004;132:995-1000.

19. Hussain K, Hindmarsh P, AynsleyGreen A. Neonates with symptomatic hyperinsulinemic hypoglycemia generate 
inappropriately low serum cortisol countrregulatory hormonal responses. J Clin Endocrinol Metab 2003;88(9):43427.

20. Senniappan S, Alexandrescu S, Tatevian $\mathrm{N}$, et al. Sirolimus therapy in infants with severe hyperinsulinemic hypoglycemia. N Engl J Med 2014;370:1131-7.

21. Stanley CH, Thornton P, Ganguly A, et al. Preoperative evaluation of infants with focal or diffuse congenital hyperinsulinism by intravenous acute insulin response test and selective pancreatic arterial calcium stimulation. J Clin Endocrinol Metab 2004;89:288-96.

22. Stanley C. Perspective on the genetics and diagnosis of congenital hyperinsulinism disorders. J Clin Endocrinol Metab 2016;101(3):815-26.

23. Snider K, Becker S, Boyajian L, et al. Genotype and phenotype correlations in 417 children with congenital hyperinsulinism. J Clin Endocrinol Metab 2013;98(2):E355-63
24. Daneshvar K, Grenacher L, Mehrabi A, Kauczor HU, Hallscheidt P. Preoperative tumor Studies using MRI or CT in patients with clinically suspected insulinoma. Pancreatology 2011;11(5):487-94.

25. Hardy OT, Hernández-Pampaloni M, Saffer JR, et al. Diagnosis and localization of focal congenital hyperinsulinism by 18F-fluorodopa PET scan. J Pediatr. 2007;150(2):140-5.

26. Anakal MG, Kalra P, Dharmalingam M, Indushekhar S, Rao V, Prassana K. Insulinoma case series: Experience of a tertiary care center. Indian J Endocrinol Metab 2014;18(6):858-62.

27. Fékété N, de Lonlay P, Jaubert F, Rahier J, Brunelle F, Saudubray JM. The surgical management of congenital hyperinsulinemic hypoglycemia in infancy. J Pediatr Surg 2004;39(3):267-9.

28. Petraitienè I, Barauskas G, Gulbinas A, et al. Congenital hyperinsulinism. Medicina 2014;50:190-5
29. Arya VB, Senniappan S, Demirbilek $\mathrm{H}$, et al. Pancreatic Endocrine and Exocrine Function in Children following Near-Total Pancreatectomy for Diffuse Congenital Hyperinsulinism. PloS one 2014;9(5):e98054.

30. Tanaka Y, Asakawa T, Asagiri K, Ayikoshi K, Hikida S, Mizote H. Nesidioblastosis treated successfully by $85 \%$ pancreatectomy. Kurume Medical J 2004;51:99-103.

31. Al-Shanafey. Laparoscopic vs open pancreatectomy for persistent hyperinsulinemic hipoglicemia of infancy. J Pediatr Surg 2009;44(5):957-61.

32. Blakely ML, Lobe TE, Cohen J, Burghen GA. Laparoscopic pancreatectomy for persistent hyperinsulinemic hypoglycemia of infancy. Surg Endosc 2001;15:897-908.

33. Bax NM, van der Zee DC, de Vroede M, et al. Laparoscopic identification and removal of focal lesions in persistent hyperinsulinemic hypoglycemia of infancy. Surg Endosc 2003;17:833. 